\title{
Croatian geomagnetic field maps for 2008.5 epoch
}

\author{
Mario Brkić ${ }^{1,{ }^{\star}}$, Danijel Šugar ${ }^{1}$, Marko Pavasović ${ }^{1}$, Eugen Vujić ${ }^{1}$, Enio Jungwirth ${ }^{2}$ \\ ${ }^{1}$ University of Zagreb, Faculty of Geodesy, Institute for Geomatics, Zagreb, Croatia \\ ${ }^{2}$ Ministry of Defense, Institute for Research and Development of Defense Systems, Zagreb, Croatia
}

\author{
Article history \\ Received September 23, 2011; accepted February 15, 2012. \\ Subject classification: \\ Geomagnetic networks, Geomagnetic surveys, Geomagnetic field, Geomagnetic anomaly.
}

\begin{abstract}
The status of the Croatian Geomagnetic Repeat Stations Network (CGRSN) and Croatian Geomagnetic Network for Field Mapping (CGNFM), completed in 2010, was described. Standard and new survey practices as well as reduction techniques were presented. The CGRSN data reduced in reference to the L'Aquila (AQU), Grocka (GCK) and Tihany (THY) observatories using weighted averages were given for the epoch 2008.5. Detailed pictures of Dalmatia's geomagnetic field of 2008.5 and the corresponding anomaly, obtained from the CGNFM data were shown.
\end{abstract}

\section{Introduction}

Geomagnetic measurements on the Croatian territory started approximately 207 years ago; a short history can be found in Brkić et al. [2003]. Updating of geomagnetic information in the Republic of Croatia started in 2002, motivated by the concrete need to update topographic and navigational maps. The aim of this paper was to present the Croatian Basic Geomagnetic Network (CBGN) upon completion in 2010, and to investigate the results of the third campaign carried out in 2008 - the geomagnetic field and anomalies of Dalmatia.

\section{Croatian Geomagnetic Repeat Stations Network}

The Croatian Basic Geomagnetic Network (Figure 1) consists of the Croatian Geomagnetic Repeat Stations Network (CGRSN) and Croatian Geomagnetic Network for Field Mapping (CGFNM); there is no national observatory present. The Croatian Geomagnetic Repeat Stations Network was established in 2004 [Brkić et al. 2006], expanded in 2008 , and reached its present form in 2009, when two repeat stations were destroyed and dislocated (Table 1 and Figure 1). Unfortunately, no secondary repeat stations were established; however, new primary repeat stations were located very close to the old ones. The average distance between repeat stations was approximately $178 \mathrm{~km}$.

Repeat stations were permanently marked with hard limestone blocks, the nearby auxiliary point with a Polyamide 6 (PA 6) peg, and a few azimuth reference points with a steel spike, as documented in the 'Position Description' form. Since azimuth marks were prone to destruction, the setup of 2 to 4 marks proved to be a reasonable practice. Repeat stations' and azimuth marks' coordinates were determined by the relative static GPS positioning method with the Trimble 4000 SSI receiver in 2004 or RTK GNSS positioning method using the Topcon HyperPro GNSS receiver in 2008, with an accuracy better than $2 \mathrm{~cm}$. After the data processing, the adjusted coordinates were transformed into the local geodetic datum where the north grid azimuths were calculated. The final true north azimuths were obtained by adding the meridian convergence values. Since the CGRSN azimuth marks were at the distance of 150 to $500 \mathrm{~m}$ from the corresponding repeat station, the error in determination of the true north azimuth was less than 39" for the closest azimuth mark.

The instruments used from 2004 onward were the Bartington D/I MAG01H fluxgate with MAG Probe A and Zeiss 010B theodolite (DI Magnetometer - DIM) with the nonmagnetic tripod, along with the GEMSys GSM-19G Overhauser Proton Precession Magnetometer (PPM). As a rule, the instruments were tested and rectified at the Laboratory for Measurements and Measuring Instruments of the Faculty of Geodesy of the University of Zagreb, and compared and calibrated at the Tihany Geophysical Observatory of the Eötvös Loránd Geophysical Institute, both before and after the surveys. (On one occasion the instruments were also compared at Fürstenfeldbruck and Belsk observatories). The final comparisons' DIMs differences were usually less than or close to $2 \mathrm{nT}$ in each base line component, and the PPMs differences less than $0.5 \mathrm{nT}$, thus the instruments were considered accurate during the surveys.

The first task in a survey was to find a repeat station, auxiliary and azimuth reference points at each location, and to check the surroundings visually for possible sources of noise. Artificial noises were excluded by checking the PPM short time records during quiet conditions. Maintaining personal magnetic hygiene, the four gradient measurements 


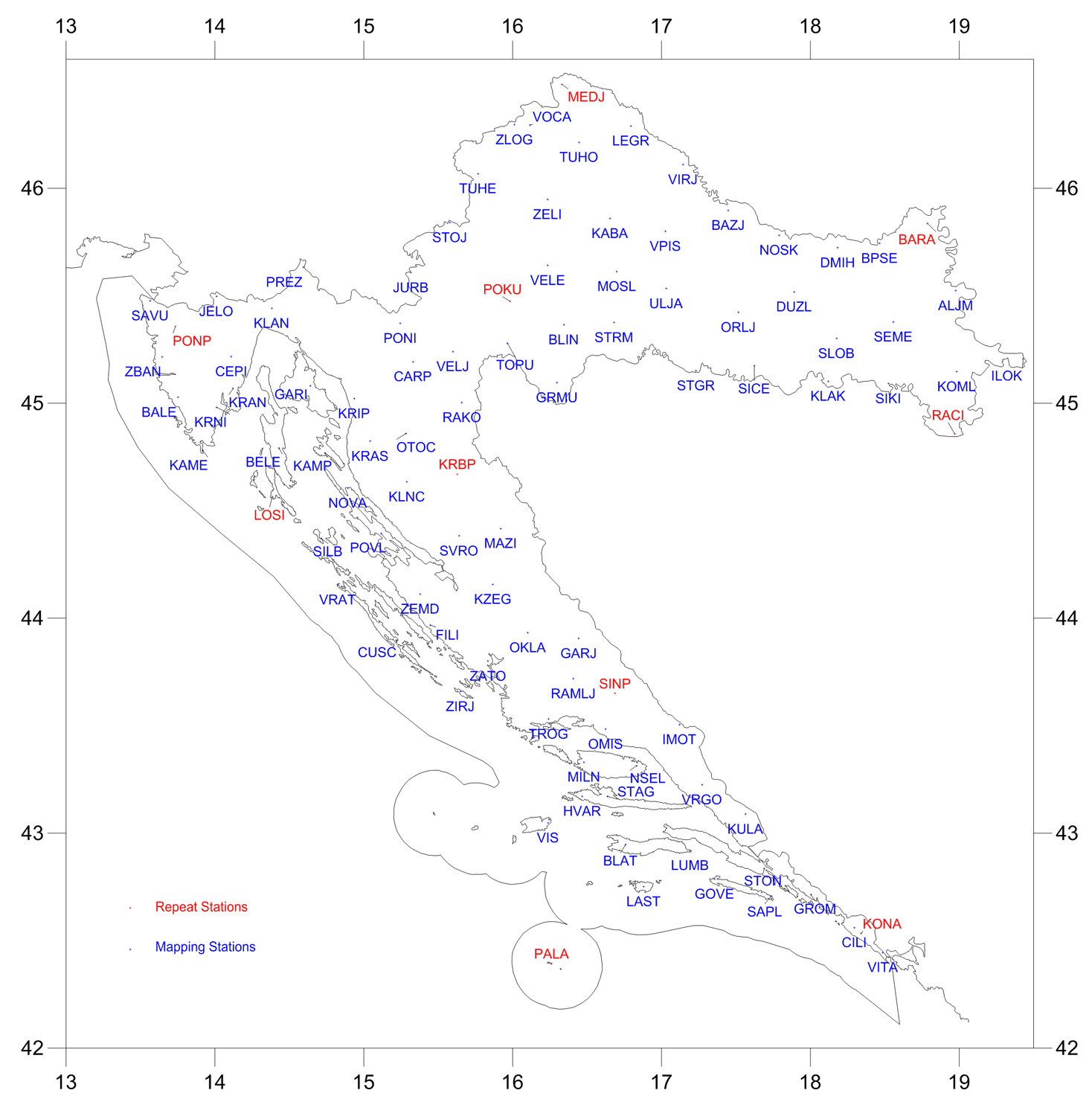

Figure 1. The Croatian Basic Geomagnetic Network. The network consists of 10 locations of CGRSN and 88 locations of CGNFM today. The network density was roughly 1 location per $663 \mathrm{~km}^{2}$ which corresponds to the current average distance between the locations of $26 \mathrm{~km}$.

\begin{tabular}{|c|c|c|c|c|c|c|c|c|c|c|c|c|}
\hline \multicolumn{2}{|c|}{ Repeat station } & \multirow{2}{*}{$\begin{array}{c}\varphi \\
\text { (dec.deg) } \\
45.47303\end{array}$} & \multirow{2}{*}{$\begin{array}{c}\lambda \\
\text { (dec.deg) } \\
15.97833\end{array}$} & \multirow{2}{*}{$\begin{array}{c}\begin{array}{c}H \\
(\mathbf{m})\end{array} \\
105\end{array}$} & \multirow{2}{*}{$\begin{array}{r}2004 \\
++\end{array}$} & \multirow{2}{*}{$\begin{array}{r}2005 \\
+\end{array}$} & \multirow{2}{*}{$\begin{array}{r}2006 \\
+\end{array}$} & \multirow{2}{*}{$\begin{array}{r}2007 \\
+\end{array}$} & \multirow{2}{*}{$\begin{array}{r}2008 \\
+\end{array}$} & \multirow{2}{*}{$\begin{array}{r}2009 \\
+\end{array}$} & \multirow{2}{*}{$\begin{array}{r}2010 \\
+\end{array}$} & \multirow{2}{*}{$\begin{array}{r}2011 \\
+\end{array}$} \\
\hline PRM01 & POKU & & & & & & & & & & & \\
\hline PRM01 & MEDJ & 46.48349 & 16.32681 & 199 & + & & & + & + & + & & \\
\hline PRM02 & MEDJ & 46.48768 & 16.33134 & 194 & & & & & & + & + & \\
\hline PRM01 & BARA & 45.83613 & 18.78178 & 86 & + & & & + & + & + & + & \\
\hline PRM01 & RACI & 44.85629 & 18.96437 & 81 & + & & & + & + & + & + & \\
\hline PRM01 & KONA & 42.53239 & 18.33525 & 47 & + & & & + & + & + & + & \\
\hline PRM01 & SINP & 43.64958 & 16.68369 & 296 & + & & & + & + & + & + & \\
\hline PRM01 & KRBP & 44.66970 & 15.62508 & 648 & + & & & + & + & + & + & \\
\hline PRM01 & PONP & 45.35572 & 13.73010 & 5 & + & & & + & + & + & + & \\
\hline PRM01 & PALA & 42.39312 & 16.25741 & 34 & & & & & + & + & + & \\
\hline PRM01 & LOSI & 44.56473 & 14.38017 & 33 & & & & & + & & & \\
\hline PRM02 & LOSI & 44.56462 & 14.38014 & 19 & & & & & & + & + & \\
\hline
\end{tabular}

Table 1. The primary repeat stations and years of surveys. The latitude and longitude were given in ETRS89, and $H$ was orthometric height. 
methods were utilized at the repeat and the auxiliary stations in order to confirm local homogeneity or to determine possible contamination. Acceptable gradients were those less than $3 \mathrm{nT} / \mathrm{m}$ and the candidate sites which did not meet this criterion were rejected. Almost all of the total field gradients found in the surveys were below $1 \mathrm{nT} / \mathrm{m}$. Thus the DIM and PPM repositioning errors were considered negligible. Observations required acceptable space weather as well as atmospheric conditions. Surveys were planned around the middle of the year and the routine consisted of the "null method" observations of declination $(D)$ and inclination $(I)$ through four or more sets early in the morning as well as late in the afternoon, during two or more days, while total intensity $(F)$ was continuously recorded at the nearby auxiliary point. A large number of measurements and their low scatter were required. If the observations exhibited suspicious scatter, more observation sets were performed, even at the cost of prolonging of occupation of the station. The azimuths to the reference marks were usually checked before and after each set of observations. The measurement's errors due to the electronics and sensor, and disagreement between the DIM probe and theodolite axes, as well as the DIM stability were controlled between observation sets. Although the null-method applied for $\mathrm{D} / \mathrm{I}$ determinations was designed to eliminate potential errors [Newitt et al. 1996], the misalignment of the fluxgate sensor as well as the offset of the fluxgate electronics were calculated according to relations given in Jankowsky and Sucksdorff [1996]. At the beginning of each D/I set, the azimuth mark was sighted in two telescope positions in order to improve the reliability of orientation and elimination of some instrumental errors (e.g. collimation error). These parameters and observations were recorded and checked for consistency in a new version of the "DIF Survey" computer programme. During the repeat stations' surveys no on-site variometer was used, with the exception of the survey carried out at the three stations during the Croatian-Hungarian project in 2010 (use of an on-site variometer proved valuable not only for reductions but also because it pointed to induction effects that still remain to be investigated).

\section{Croatian Geomagnetic Network for Field Mapping}

The Croatian Geomagnetic Network for Field Mapping aimed at dense mapping of the geomagnetic field in order to update geomagnetic information on official and military maps and provide more accurate scientific models. Because of the large total number of mapping stations, as well as limited resources, the CGNFM establishment and survey started in Dalmatia in 2008, continued in Istria, northern islands and western Croatia in 2009, and ended in Slavonia and northern Croatia in 2010 (Figure 1). Approximately 30 stations of the CGNFM were surveyed during the summer months of each year. CGFNM consists of 88 mapping stations today. In order to connect these three parts of the CGNFM, the re- peat stations (Table 1) were also surveyed in the same years.

Besides common issues, such as the current situation concerning mines, each year and region brought its own peculiarities to which adaptation was required. In Dalmatia 2008 campaign the specifics included distribution and (non)existence of GPS and trigonometric points used in RTK GNSS, organizational and logistic issues especially on the southern islands, and a number of sites with geological noise (higher gradients). This noise was noticed on the sites with terra rossa, thus leading to the assumption of their correlation, which was investigated in Istria in the following year. Contribution of terra rossa to the total intensity gradients was confirmed, but significant correspondence between terra rossa and geomagnetic elements was not proved [Šugar et al. 2011]. In Istria and northern islands 2009 campaign the choice of locations was governed mainly by the presence of artificial noises (detected by PPM), most times of unknown origins. The noise was also an issue in northern Croatia, due to Slovenia DC railways, as well as Zagreb sources, in addition to heavy rains and floods in Slavonia and particularly Baranja in 2010. The same year an expedition to the volcanic island of Jabuka finally succeeded and revealed a large negative total intensity anomaly [Brkić et al. 2012].

The actual procedure of the mapping stations' setup and survey was similar to the one in case of repeat stations [Brkić et al. 2006, Vujić et al. 2011]; however some criteria were relaxed, e.g. low gradient criteria was set to $5 \mathrm{nT} / \mathrm{m}$; the laborious outer grid gradiometry method was replaced by a simpler and quicker modified cross gradiometry method (a method based on cross method [Newitt et al. 1996]); gradiometer measurements are performed in $10 \mathrm{~m} \times 10 \mathrm{~m}$ NS and WE lines with $1 \mathrm{~m}$ step. Gradients are estimated not only in cardinal directions, but also in NW, SW, SE and NE directions.); RTK GNSS involved CROPOS network service (http: / www. cropos.hr/) in 2009 and 2010, yielding faster and more inexpensive coordinates determination; and each station was usually occupied only for one day, so less DI sets were performed in comparison to the repeat station survey practice.

\section{Geomagnetic field of 2008.5}

Following the procedure outlined above, the new repeat and mapping stations' setup and survey took place between April 26 and September 11 of 2008. The total errors include those originating from instruments, measurements, positioning and reduction. Before the survey, the PPM and DIM were checked at the Faculty of Geodesy and Tihany Geophysical Observatory. The difference found between the Croatian and Hungarian PPMs was $0.13 \mathrm{nT}$. Comparison of DIMs led to calibration of the Bartington Mag A probe and MAG $-01 \mathrm{H} \mathrm{elec-}$ tronic unit; the final differences of $(\Delta X, \Delta Y, \Delta Z)$ base line components were $0.01 \mathrm{nT}, 2.23 \mathrm{nT}$ and $0.02 \mathrm{nT}$. During the survey the PPM crashed, and was repaired and tested at GEMSys Canada. After the survey, the Faculty of Geodesy and Fac- 
ulty of Science PPMs difference was $0.2 \mathrm{nT}$, and the differences of $(\Delta X, \Delta Y, \Delta Z)$ base line components at Tihany were $0.70 \mathrm{nT}$, $-0.34 \mathrm{nT}$ and $-0.41 \mathrm{nT}$. The positioning and measurements' errors were controlled by the precise centering of the instruments at permanent marks at low gradients and sites free of artificial noise, by checking the azimuths to the reference marks during the observations, by performing the observations in appropriate weather and space weather conditions (i.e. during $\mathrm{Kp} \leq 3$ ), and requiring low scatter of row observations.

\subsection{Reductions}

A peculiarity of all Croatian surveys and reductions was the nonexistence of a national geomagnetic observatory, which was compensated by the relative proximity of THY, AQU, and GCK observatories (the maximum distance between the stations and the observatories was $581 \mathrm{~km}$ ). In order to get 2008.5 epoch internal geomagnetic field by reduction of the 2008 observations, a simple model was utilized, based on the assumption that all time (external, induced, as well as secular) variations at the observatory $O$ and station $S$ were equal [Meloni et al. 1994, Newitt et al. 1996, De Santis et al. 1997],

$$
E_{S}^{\text {epoch }}=E_{\mathcal{S}}\left(t_{m}\right)-E_{0}\left(t_{m}\right)+E_{0}^{\text {eppoch }}
$$

where $E_{S}\left(t_{m}\right)$ denotes the geomagnetic element at the station and measurement time $t_{m}, E_{0}\left(t_{m}\right)$ the value of that element at the same instant at the observatory, and $E_{S}^{\text {epoch }}$ and $E_{0}^{\text {epoch }}$ the values at some epoch at the station and the observatory, respectively. Each individual observation was reduced to the epoch 2008.5 and in reference to nearby observatory using INTERMAGNET data, and averaged to obtain the particular representative geomagnetic element value at the station. The similar procedure was applied to the reduction of 2004 and 2007 repeat station data [Vujić et al. 2011]; since the expected difference between the simple reduction method, and the method in which the secular variation differs at the station and observatory, was not large (the maximum differences between the averaged solutions obtained by these two methods being 11 " for $D, 7$ " for $I$ and $0.5 \mathrm{nT}$ for $F$ for epoch 2007.5), the simple method was chosen to reduce 2008 measurements.

Slightly different, particular solutions for the CGRSN survey data were obtained at the repeat stations when the chosen reference observatory was either THY, AQU or GCK: the maximum AQU - THY, GCK - THY and AQU - GCK differences between particular CGRSN solutions were 1.9', 0.7', and $1.9^{\prime}$ for $D, 0.4^{\prime}, 0.2^{\prime}$, and $0.4^{\prime}$ for $I$, and $5.5 \mathrm{nT}, 3.3 \mathrm{nT}$, and $5.0 \mathrm{nT}$ for $F$, respectively. In all three solutions the scatter, i.e.

$$
\max \left\{\mid\left(E_{S}^{\text {epoch }}-\bar{E}_{S}^{\text {epoch }} \mid\right\},\right.
$$

was less than or very close to the targeted accuracies ( 1 ' for $D, 30$ " for $I$, and $5 \mathrm{nT}$ for $F$ ). In addition, an averaged solution that includes $n=3$ particular solutions, in reference to the THY, AQU and GCK observatories, was calculated as

$$
\left(\bar{E}_{S}^{\text {epoch }}\right)_{w}=\frac{\sum_{i=1}^{n}\left(w_{i} \cdot\left(\bar{E}_{S}^{\text {epoch }}\right)_{i}\right)}{\sum_{i=1}^{n} w_{i}},
$$

where the empirical weight $w_{i}$ was set equal to the inverse square of the standard deviation of the differences $E_{S}\left(t_{m}\right)-$ $\mathrm{E}_{0}\left(t_{m}\right)$. The averaged solution was found comparable to the previous particular solutions. The corresponding scatter of the averaged solution $\left(\bar{E}_{S}^{\text {epoch }}\right)_{w}$ was defined as

$$
\max \left\{\left|\left(\bar{E}_{S}^{\text {epoch }}\right)_{i}-\left(\bar{E}_{S}^{\text {epoch }}\right)_{w}\right|\right\} .
$$

\begin{tabular}{|c|c|c|c|c|c|c|}
\hline 2008.5 & $\begin{array}{c}D \\
\text { (dec.deg) }\end{array}$ & $\begin{array}{l}\text { Scatter } D \\
\text { (dec.min) }\end{array}$ & $\begin{array}{c}I \\
\text { (dec.deg) }\end{array}$ & $\begin{array}{c}\text { Scatter } I \\
\text { (sec.) }\end{array}$ & $\begin{array}{c}\mathbf{F} \\
(\mathbf{n T})\end{array}$ & $\begin{array}{c}\text { Scatter } F \\
\quad(\mathbf{n T})\end{array}$ \\
\hline BARA & 3.431 & 0.2 & 62.525 & 6 & 47855.7 & 2.1 \\
\hline KONA & 2.947 & 0.3 & 59.256 & 4 & 46888.0 & 2.5 \\
\hline KRBP & 2.615 & 0.3 & 61.235 & 4 & 47144.5 & 1.3 \\
\hline LOSI & 2.610 & 0.3 & 61.310 & 16 & 47291.5 & 4.0 \\
\hline MEDJ & 2.796 & 0.8 & 62.929 & 23 & 47869.3 & 2.7 \\
\hline PALA & 2.797 & 0.4 & 58.895 & 14 & 46593.8 & 2.2 \\
\hline POKU & 2.834 & 0.1 & 62.011 & 13 & 47550.6 & 1.8 \\
\hline PONP & 2.302 & 0.6 & 61.765 & 10 & 47338.6 & 2.4 \\
\hline RACI & 3.340 & 0.2 & 61.543 & 15 & 47571.7 & 2.9 \\
\hline SINP & 2.644 & 0.1 & 60.477 & 10 & 47036.0 & 2.2 \\
\hline
\end{tabular}

As in Vujić et al. [2011], the appropriateness of data for the reduction was checked by cross-correlation of total in-

Table 2. CGRSN data reduced to epoch 2008.5. 
tensity time series at each station and observatory; additionally, multilinear regression was used to deduce how the variations of the total intensity at stations are approximated by the variations at the observatories. The global geomagnetic disturbance index Kp was $\leq 3$ at all the observation times. All the observatories were included in the averaged solution for all the repeat stations except for LOSI, where particular $D$ solutions in reference to GCK and THY were excluded because of considerable scatter. In this case a discrepancy in time variations between the station and observatories was reflected in the calculated $F$ correlations as well. For most stations the averaged solution scatter was less than or comparable to particular scatters; thus the weighted averaged solution was preferred as definitive for the epoch 2008.5 (Table 2). As expected, differences of the definitive solution to IGRF-11 (http:/ / www.ngdc.noaa.gov/) were pronounced: the maximum difference at the repeat stations was $14^{\prime}$ for $D, 19^{\prime}$ for $I$, and $141.0 \mathrm{nT}$ for $F$.

Mapping stations surveyed in 2008 were reduced in the same manner as for the repeat stations above, and the definitive solution was chosen to be the weighted averaged solution.

The average values of all repeat and mapping stations surveyed in 2008 and reduced to the epoch 2008.5 were $2.715^{\circ}$ for $D, 60.3769^{\circ}$ for $I$, and $47128.5 \mathrm{nT}$ for $F$, with maximum scatters $0.8^{\prime}$ for $D, 25^{\prime \prime}$ for $I$, and $4.6 \mathrm{nT}$ for $F$.

The 2007.5-2008.5 annual change was estimated as a difference in geomagnetic elements at the same repeat stations (Table 3). The average annual change over Croatian territory was $6^{\prime} /$ year for $D, 7^{\prime \prime} /$ year for $I$, and $29.8 \mathrm{nT} /$ year for $F$; the annual change increased slightly in comparison to the 2004.52007.5 period. The inclination annual change was almost negligible. Maximum differences of annual change to the one estimated from IGRF-11 were rather low: less than $1^{\prime} /$ year for $D, 15^{\prime \prime} /$ year for $I$, and $3 \mathrm{nT} /$ year for $F$.

\subsection{Normal field}

As an estimation of the main field, the Croatian Geomagnetic Normal Reference Field (CGNRF) for the epoch 2008.5 was obtained from the Table 2, and the L'Aquila (AQU), Fürstenfeldbruck (FUR), Tihany (THY), Grocka (GCK) and Panagjurishte (PAG) observatories 2008.5 annual means similarly to Vujić et al. [2011]. The geomagnetic element $E_{\text {normal }}$ was represented by the second order polynomial in latitude and longitude:

\begin{tabular}{cccc}
\hline $\begin{array}{c}\text { Annual change } \\
\mathbf{2 0 0 7 . 5 - 2 0 0 8 . 5}\end{array}$ & $\boldsymbol{D}^{\text {'/yr. }}$ & $\boldsymbol{I}$ "/yr. & $\boldsymbol{F} \mathbf{n T} / \mathbf{y r}$. \\
\hline BARA & 6.1 & 9 & 28.7 \\
KONA & 5.5 & 7 & 27.9 \\
KRBP & 6.1 & 5 & 30.1 \\
MEDJ & 7.0 & 7 & 31.8 \\
POKU & 5.8 & 3 & 27.9 \\
PONP & 6.4 & 1 & 29.5 \\
RACI & 6.3 & 14 & 33.0 \\
SINP & 5.1 & 12 & 29.2 \\
\hline
\end{tabular}

Table 3. The annual change in the period from 2007.5 to 2008.5.

$$
\begin{gathered}
E_{\text {normal }}=c_{0}+c_{1}\left(\lambda-\lambda_{0}\right)+c_{2}\left(\varphi-\varphi_{0}\right)+c_{3}\left(\lambda-\lambda_{0}\right)^{2}+ \\
+c_{4}\left(\varphi-\varphi_{0}\right)\left(\lambda-\lambda_{0}\right)+c_{5}\left(\varphi-\varphi_{0}\right)^{2}
\end{gathered}
$$

where $\varphi_{0}=44.6941^{\circ}$ and $\lambda_{0}=16.8333^{\circ}$ were the reference coordinates' values. The coefficients $c_{0}, c_{1}, \ldots, c_{5}$ were the unknowns determined from the $N$ reduced repeat stations measurements through the weighted least squares fitting procedure:

$$
\sum_{i=1}^{N} w_{i}\left(\left(E_{S}^{\text {epoch }}\right)_{i}-E_{\text {normal }}\right)^{2}=\min .
$$

To check for possible contaminations coming from the sites in anomalous areas, the Chauvenet's criterion was applied in the fit, where standard uncertainty was:

$$
\sigma=\sqrt{\frac{\sum_{i=1}^{N}\left(\left(E_{S}^{\text {epoch }}\right)_{i}-E_{\text {normal }}\right)^{2}}{(N-6)}}
$$

[see e.g. Meloni et al. 1994 or Kovács and Körmendi 1999]. In our case, all sites had the residuals less than $2 \sigma$, thus none of them was rejected. Prior to the calculation of the normal field, total intensity was additionally corrected to the sea level (by multiplying (5) with term $\left(1-3 h / R_{e}\right)$, where $h$ was the station height, and $R_{e}$ the mean Earth radii [see, e.g., Meloni et al. 1994.], but no additional correction was applied to angular elements.

\begin{tabular}{|c|c|c|c|c|c|c|}
\hline$E_{\text {normal }}$ & $c_{0}$ & $c_{1}$ & $c_{2}$ & $c_{3}$ & $c_{4}$ & $c_{5}$ \\
\hline$D\left(^{\circ}\right)$ & 2.894 & 0.1729 & 0.06840 & -0.0002617 & 0.02176 & 0.003314 \\
\hline$I\left({ }^{\circ}\right)$ & 61.382 & 0.051400 & 0.95595 & -0.0010133 & -0.012053 & -0.035960 \\
\hline$F(\mathrm{nT})$ & 47380.6 & 61.2101 & 304.002 & -3.38011 & -3.31730 & -0.166120 \\
\hline
\end{tabular}

CGNRF declination, inclination and total intensity coefficients for the epoch 2008.5 were given in Table 4. The approximate displacement of isogones was westward, iso-

Table 4. The coefficients of the CGNRF 2008.5. 


\begin{tabular}{|c|c|c|c|c|c|c|}
\hline $\begin{array}{c}\text { CGNRF } \\
\text { annual change }\end{array}$ & $c_{0}$ & $c_{1}$ & $c_{2}$ & $c_{3}$ & $c_{4}$ & $c_{5}$ \\
\hline$D(1 /$ yr. $)$ & 5.93 & -0.00283 & 0.222 & 0.0249 & 0.0281 & -0.00984 \\
\hline$I$ ("/yr.) & 9.4 & 2.1 & 1.1 & -0.53 & -0.94 & -0.40 \\
\hline$F(\mathrm{nT} / \mathrm{yr}$.) & 30.0 & 0.0830 & 0.307 & 0.0116 & 0.0201 & -0.221 \\
\hline
\end{tabular}

Table 5. The coefficients of the CGNRF annual change 2007.5-2008.5.

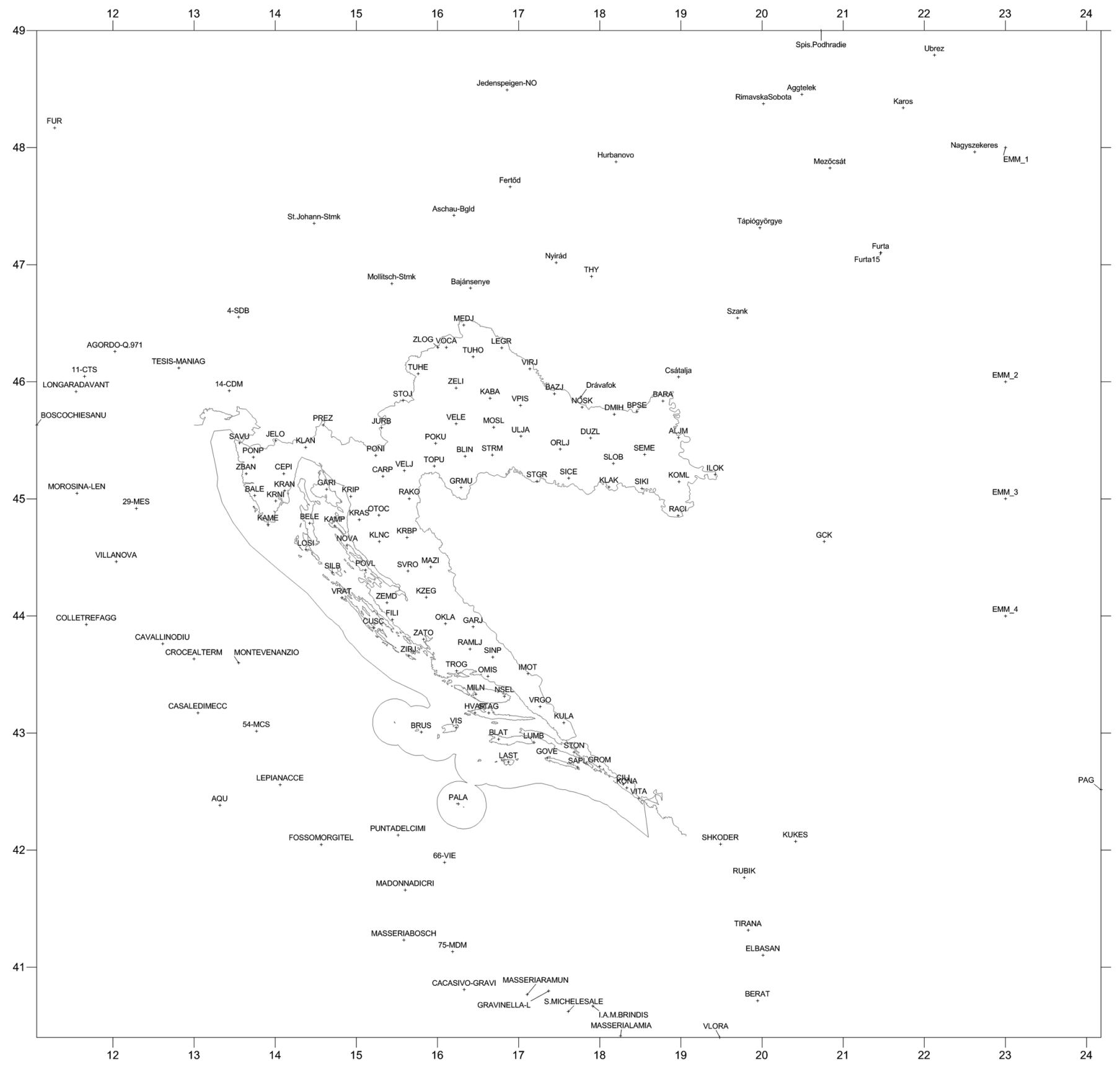

Figure 2. Data points used to obtain 2008.5 geomagnetic field maps.

dynames to the southwest, and the one of isoclines was negligible, continuing the general behavior noticed for normal fields in the period 2004.5-2007.5.

The self-consistency of the normal field was checked through the geometrical incoherence $\Delta F=F-\sqrt{H^{2}+Z^{2}}$ [Meloni et al. 1994]. The $D, I$ and $F$ were measured and their normal fields were found directly. On the other hand, the normal fields of horizontal and vertical components were derived using $H=F \cos I$ and $Z=F \sin I$. The absolute geometrical incoherence found over Croatia was less than $4 \mathrm{nT}$. A slight increase of that value in respect to the 2004.5-2007.5 may be attributed to different methods as well as additional 
(new) stations involved in the reduction.

The maximum difference of CGNRF 2008.5 and IGRF11 at repeat stations was $-9.1^{\prime}$ for $D, 8.2^{\prime}$ for $I$, and $-57.2 \mathrm{nT}$ for F; similar F statistics were found for the 2004.5 and 2007.5 epochs. Additionally, it was found that the CGNRF 2008.5 model was equivalent to the SHA maximum degree 92 and the minimum wavelength was approximately $435 \mathrm{~km}$ [Bullard 1967]; thus, besides the core field, the normal field contained small contribution from the lower crust.

\subsection{Normal field annual change}

It was crucial to use the same set of stations and observatories (as well as procedures) in both epochs contributing the normal annual change. The 2007.5-2008.5 normal annual change was represented by the polynomial of the form (5), with the coefficients given in Table 5 .

The average 2007.5-2008.5 normal annual change at repeat stations was $6 \%$ year for $D, 8^{\prime \prime} /$ year for $I$, and 29.8 $\mathrm{nT} /$ year for $F$. Though the normal annual change increased in comparison to the 2004.5-2007.5 period, the overall behavior remained similar. The normal annual change was almost equal to the annual change found as a direct difference in geomagnetic elements at the repeat stations.

Similarly, the maximum difference of the normal to the IGRF-11 annual change was less than 1 '/ year for $D, 15$ "/ year for $I$, and $3 \mathrm{nT} /$ year for $F$.

\subsection{Geomagnetic field and anomaly maps}

In order to obtain more realistic result, geomagnetic maps of 2008.5 were produced using 165 data points: besides 10 repeat stations and 29 mapping stations (and Brusnik for F) surveyed in 2008 and reduced to 2008.5, there were 59 other Croatian mapping stations data from 2009.5 and 2010.5 epochs, AQU, FUR, THY, GCK and PAG 2008.5 data, 45 Slovakian, Austrian, Hungarian and Italian data of various epochs from British Geological Survey (http: / / www. geomag.bgs.ac.uk/), 12 Hungarian repeat stations 2008.5 data and 4 Enhanced Magnetic Model (http: / / www.ngdc. noaa.gov/) 2008.5 data points close to the eastern edge of the map (Figure 2).

Data inside the Croatia not referring to 2008.5 was reduced firstly to the central epoch for the years of surveys, i.e. 2009.5 and 2010.5 in the same manner as described above, and then to epoch 2008.5 by 2008.5-2009.5 and 2009.5-2010.5 normal annual changes. The data outside the Croatia not referring to 2008.5 was reduced by IGRF-11. Maps (Figures 3-5) were generated in Surfer software by using Radial Basis Function as an exact interpolator.

Thus a more detailed view of the geomagnetic field in Dalmatia surveyed in 2008 was developed (upper part of Figures 3-5), reflecting the main features of Mokrović [1928] and Goldberg [1952] maps. The corresponding declination, inclination and total intensity anomalies (lower part of Figures
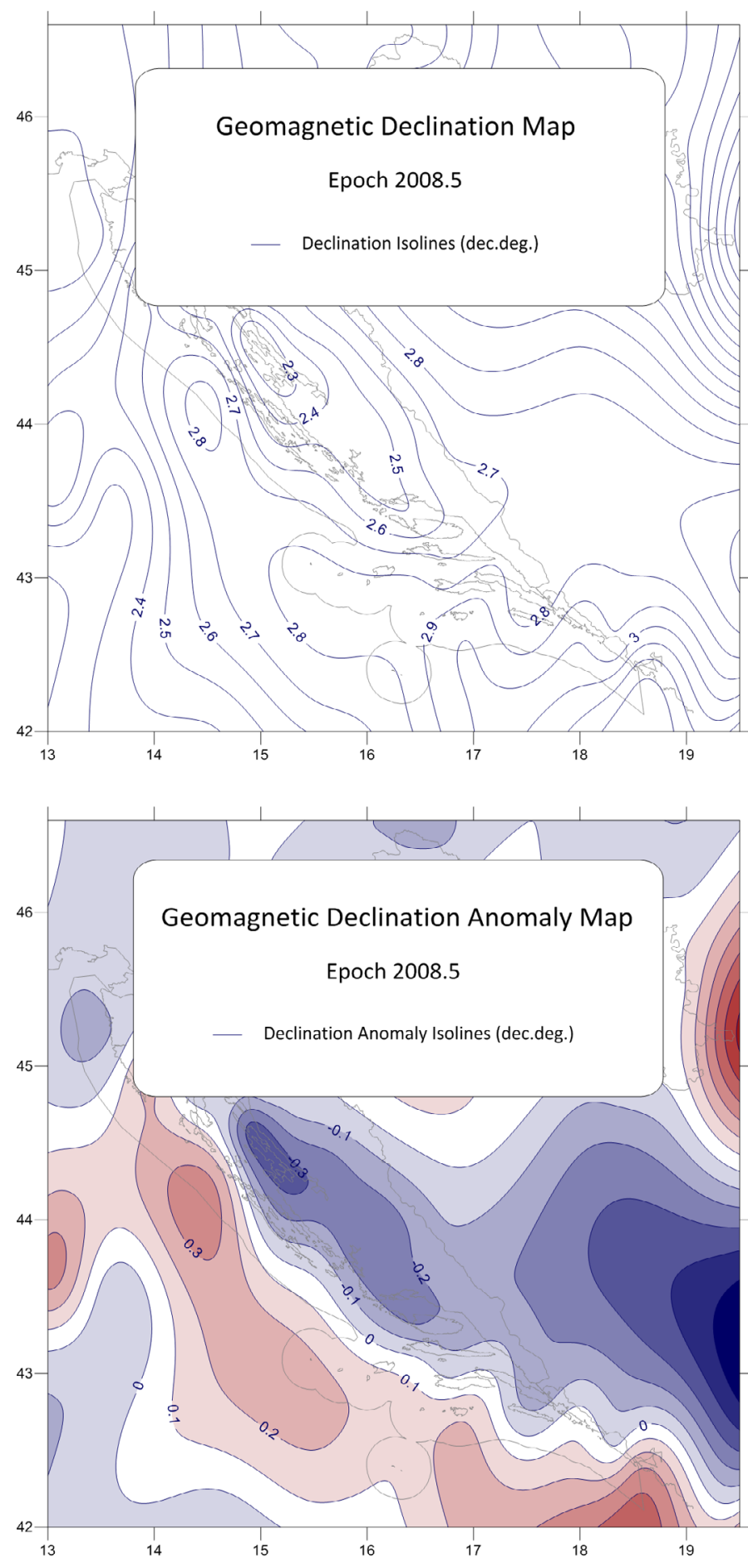

Figure 3. Declination and its anomaly at 2008.5 .

3-5) were found as the differences between the reduced and normal field data calculated in mentioned data points for epoch 2008.5. The maximum anomalies at stations were $16.5^{\prime}$ for $D, 16.0^{\prime}$ for $I$, and $474.0 \mathrm{nT}$ for $F$. According to these figures, none of the repeat stations was located on completely anomaly free site.

\section{Conclusion}

Starting from scratch, it took almost ten years to establish and survey the Croatian Basic Geomagnetic Network as well as to obtain the first updated maps. The 2008.5 epoch re- 

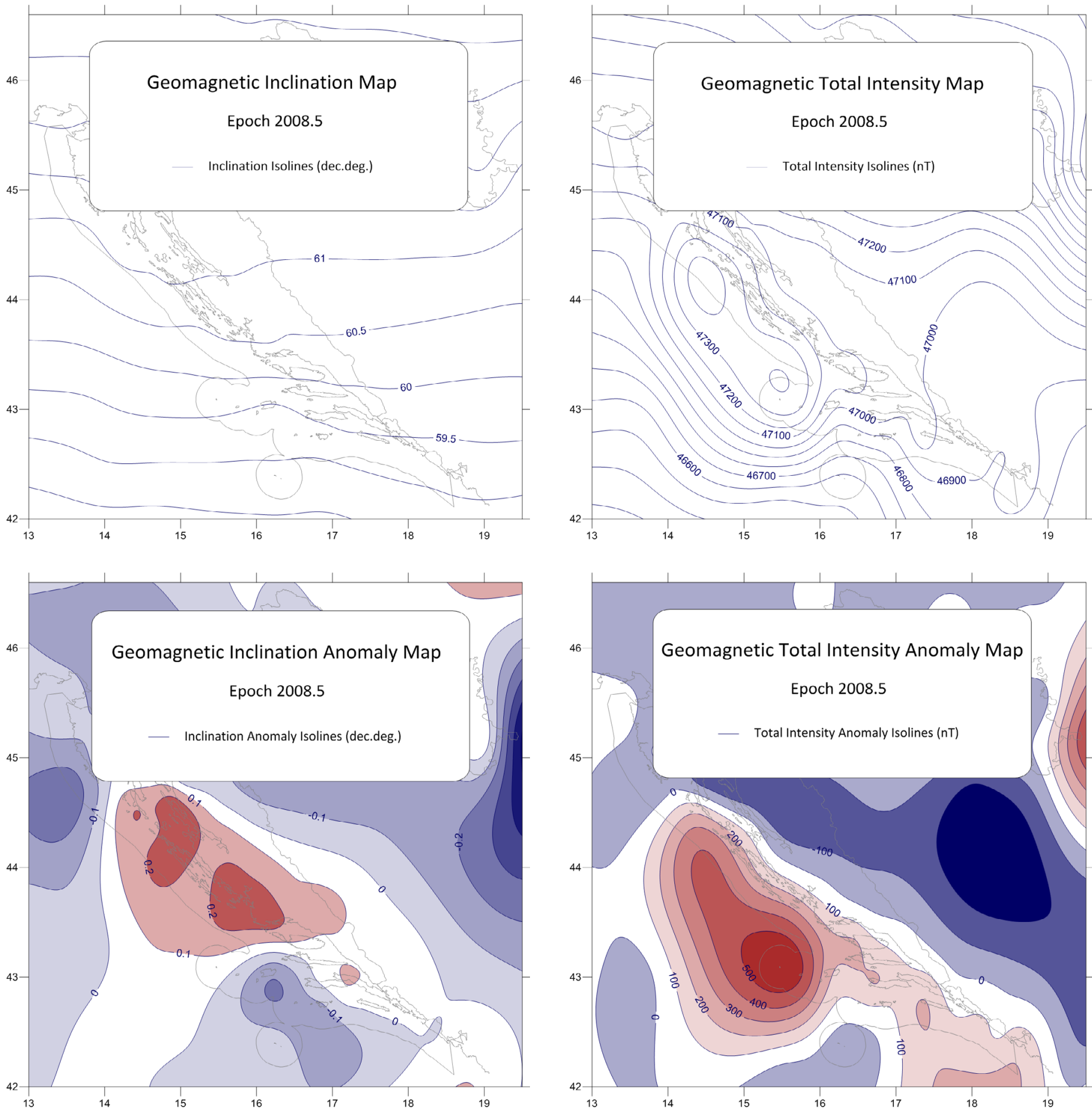

Figure 4 (above, top and bottom). Inclination and its anomaly at 2008.5.

sults presented here showed acceptable accuracies, and the normal field maps exhibited consistency of behavior in the recent years. Although the normal field annual change was found close to the IGRF-11 annual change, their differences reconfirmed the need for continuation of the repeat stations surveys when highest accuracies are needed. Dense mapping of Dalmatia in 2008 revealed the presence of non-negligible anomalies. The bulk mid-Adriatic anomaly was also recognized. The repeat stations were found to be not far from the optimum positions; however, the presented anomalies' maps should be considered in the networks revision. In order to

Figure 5 (above, top and bottom). Total intensity and its anomaly at 2008.5.

minimize induction effects, as well as external time variation, future surveys call for use of the on-site variometer. Finally, in order to provide continuous observations, more reliable and independent reductions and models, establishment of a national observatory would be an essential next step.

Acknowledgements. The establishment and surveys of the geomagnetic networks were funded by Croatia's Institute for Research and Development of Defense Systems of the Ministry of Defense, State Geodetic Administration, and Ministry of Science, Education and Sports. Special thanks to the AQU, FUR, THY, GCK and PAG observatories as well as INTERMAGNET and BGS for providing the data. 


\section{References}

Brkić, M., T. Bašić and G. Verbanac (2003). Geomagnetism in Croatia - a Historical Overview, Geodetski list, Zagreb, 183-194.

Brkić, M., D. Šugar, M. Rezo, D. Markovinović and T. Bašić (2006). Croatian Geomagnetic Repeat Stations Network, "Geomagnetics for Aeronautical Safety: A Case Study in and around the Balkans", NATO Security through Science Series, Proceedings of the NATO Advanced Research Workshop on New Data for the Magnetic Field in the former Yugoslav Republic of Macedonia for Enhanced Flying and Airport Safety, Ohrid, 18-22 May 2005, Springer.

Brkić, M., D. Špoljarić and D. Markovinović (2012). Geomagnetic and GNSS survey of the island Jabuka peak, Geodetski list, Zagreb, vol. 65 (88) no. 3, 195-204 (in Croatian).

Bullard, E.C. (1967). The removal of trend from magnetic surveys, Earth Planet. Sci. Lett., 2, 293-300.

De Santis, A., M. Chiappini, G. Dominici and A. Meloni (1997). Regional geomagnetic field modelling: the contribution of the Istituto Nazionale di Geofisica, Annali di Geofisica, 40 (5), 1161-1169.

Goldberg, J., J. Baturić, J. Mokrović and M. Kasumović (1952). Determination of magnetic declination in Yugoslav part of the Adriatic sea in 1949, Discussion Mat. Inst. Hist. Sci. -Mat. Med. YASA, 1/2, 13-43, Zagreb (in Croatian).

Kovács, P., and A. Körmendi (1999). Geomagnetic repeat station survey in Hungary during 1994-1995 and the secular variation of the field between 1950 and 1995, Geophysical Transactions, 42 (3/4), 107-132.

Jankowski, J., and C. Sucksdorff (1996). Guide for magnetic measurements and observatory practice, IAGA, Warsaw.

Meloni, A., O. Battelli, A. De Santis and G. Dominici (1994). The 1990.0 magnetic repeat station survey and normal reference fields for Italy, Annali di Geofisica, 37 (5), 949-967.

Mokrović, J. (1928). Razdioba glavnih elemenata zemaljskog magnetizma u kraljevini Srba, Hrvata i Slovenaca, Rad Geofiz. zavoda u Zagrebu, 3-14, Zagreb (in Croatian).

Newitt, L.R., C.E. Barton and J. Bitterly (1996). Guide For Magnetic Repeat Station Surveys, IAGA, Boulder, USA.

Šugar, D., E. Jungwirth and M. Rezo (2011). Geomagnetic Elements Determination on the Selected Locations with the Red Soil (Terra Rossa), Geodetski list, Zagreb, 3, 241259 (in Croatian).

Vujić, E., M. Brkić and N. Radović (2011). Analysis of Croatian geomagnetic repeat station surveys of 2004 and 2007, Studia Geophysica et Geodaetica, 55 (4), 737-753.

\footnotetext{
${ }^{\star}$ Corresponding author: Mario Brkić,

University of Zagreb, Faculty of Geodesy, Institute for Geomatics,

Zagreb, Croatia; email: mbrkic@geof.hr.

C 2012 by the Istituto Nazionale di Geofisica e Vulcanologia. All rights reserved.
} 